\title{
419
}

\section{As pessoas nos não-lugares. Ou as não-pessoas precisam de lugares ${ }^{1}$}

\section{Sara Machado da Graça}

Sou cenógrafa e figurinista. Como tal, gosto de apreciar todas as ricas personagens que se cruzam comigo diariamente no "cenário" de Maputo, cidade em constante bulício colorido, confuso, fluído apesar de caótico e misto de toda a panóplia de emoções. Para quem anda a pé, para quem conduz, para quem anda de chapa, de my love... para cada um há visões diferentes e os ritmos são muitos e muito diversos a coexistir, mas o movimento é constante. É uma cidade que cresceu exponencialmente durante a guerra civil, resultado do êxodo rural, sem ter estrutura para suportar esse excesso demográfico. À cidade "de cimento", colonial, acrescentaram-se os bairros suburbanos que cresceram desordenadamente, sem plano nem condições sanitárias, onde vive a maioria da população residindo em casas construídas em blocos de cimento e chapa de zinco. Uma grande parte das famílias subsistem através do mercado informal, vendendo os produtos das suas pequenas machambas (hortas) ou itens de toda a espécie, importados da África da Sul.

\section{As figuras desumanizadas}

Quando fotografei estas personagens de Maputo, não sabia que ia depois trabalhá-las, apenas colecionava imagens dos vendedores de rua como atores-marioneta nos diferentes cenários que ia descobrindo. Estas personagens fundem-se com a paisagem, fazem parte dela, mesclam-se numa coreografia cenográfica, urbana e identitária da cidade.

\footnotetext{
${ }^{1}$ Estas imagens não são profissionais, não as fiz para publicar, a qualidade técnica é reduzida, porque são ficheiros já antigos, cópias dos originais. Todas as fotografias usadas para as montagens são originais meus.
} 
Estas pessoas-signo eram uma presença fortíssima nas imagens que fazem parte do meu dia-a-dia - o homem água, o homem almofadas, o homem zips, o homem das tomadas elétricas, o dos óculos, as mulheres carregadas com carga à cabeça... agentes do dumba nengue (mercado informal) geral que circulam, cada um a seu passo, etéreos, estátuas da identidade urbana moçambicana - recolectores, "homem-anúncio", sucateiros, recicladores dos seus produtos - que tomam formas dignas dos bailarinos triádicos de Oscar Schlemmer, numa espécie de dança sobre um itinerário infinito de ícones pop do espaço africano do consumo.

Marc Augé define "não-lugares" como "lugares transitórios que não possuem significado suficiente para serem definidos como um lugar" (1994, p. 10). Segundo o autor, estes espaços são representativos da afirmação da existência da sobremodernidade, participando na antropologia urbana como associados aos viajantes "o espaço do viajante seria assim, o arquétipo do não-lugar". O movimento acrescenta à coexistência dos mundos e à experiência combinada do lugar antropológico e daquele que não o é mais (pela qual Starobinski define, em suma, a modernidade) a experiência particular de uma forma de solidão, e, em sentido literal, de uma "tomada de posição" - a experiência daquele que, diante da paisagem que é obrigado a contemplar, "toma a posse" e tira da consciência dessa atitude um prazer raro e, às vezes, melancólico. Portanto, não é de espantar que seja, entre os "viajantes" solitários do século passado, (...) viajantes acidentais, que estejam aptos a encontrar a evocação profética de espaço, onde nem a identidade, nem a relação, nem a história fazem realmente sentido, onde a solidão é sentida como superação ou esvaziamento da individualidade, onde só o movimento das imagens deixa entrever, por instantes, àquele que as olha a fugir, a hipótese de um passado e a possibilidade de um futuro" (1994, p.80-81).

\section{As não-pessoas precisam de lugares}

Num segundo momento senti que estas personagens tinham alma, eram pessoas, únicas, solitárias, resilientes e presas ao quotidiano da sobrevivência. Lembravam o Acendedor de Lampiões do Pequeno Príncipe de St Exupéry ou as personagens do universo absurdo de Samuel Beckett, entidades poéticas e simbólicas enredadas num ciclo semelhante aos tormentos de Sísifo.

"Pediam" para estar noutro sítio, longe dali, num espaço feito só para eles.

Tentei dar-Ihes espaços aparentemente transitórios, mas onde a viagem pudesse tornar-se o destino, e que esse fosse o espaço identitário de conforto para que as negativas (não-lugar, não-pessoa) se anulassem e para que pudéssemos ter uma pessoa no seu lugar. 
Mediterranean; taken and transplanted by early Spanish colonialists from the Canary Islands to the Americas, and distributed by European botanists to and from colonies in Asia, Africa and the Antipodes, and back to Europe, palms have become the symbol of successful uprooted-ness: synonymous with tropical views, pre-lapsarian lands, and exotic holidays.

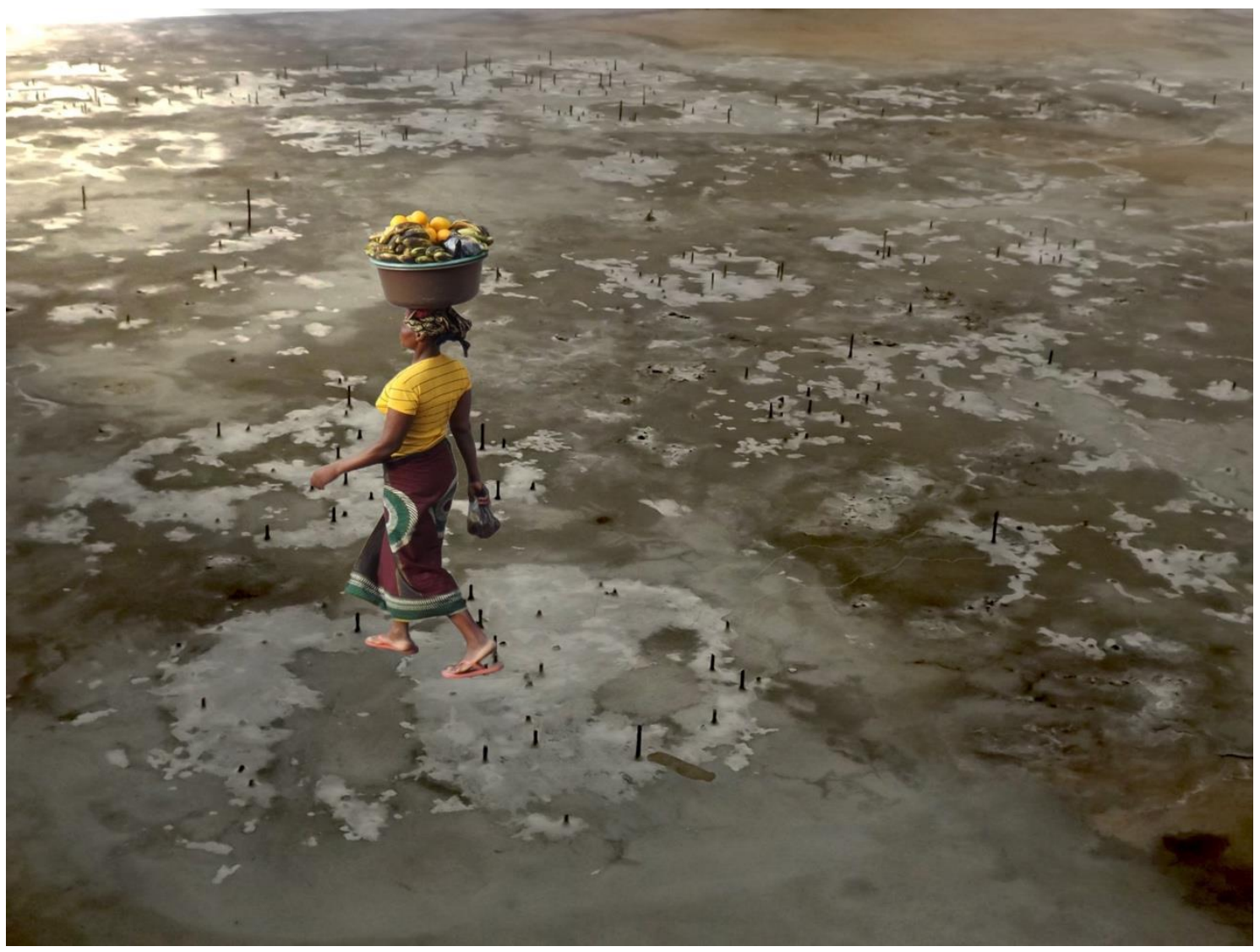

Mamã das frutas, Sara Machado da Graça, 2019 


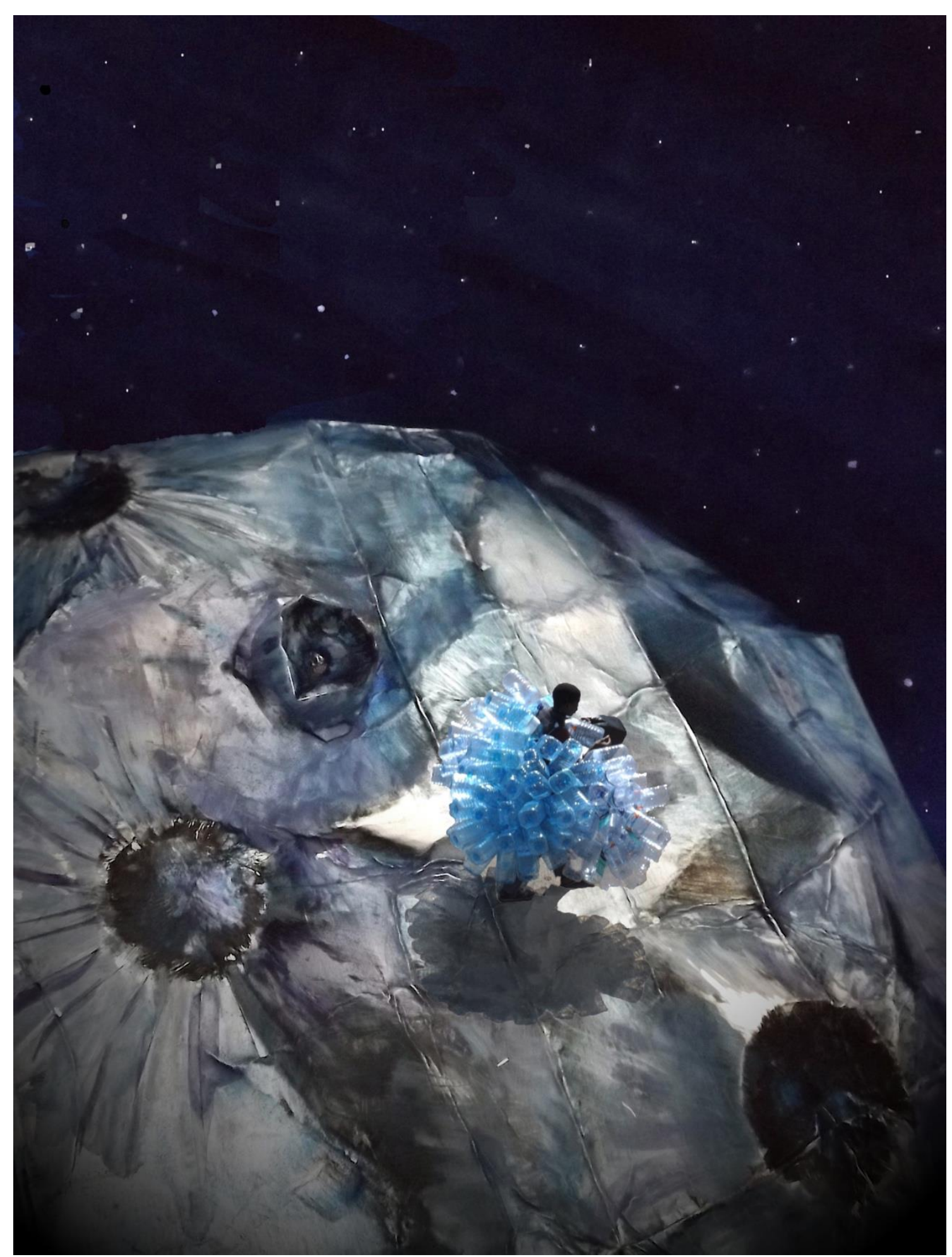

Man on the moon, Sara Machado da Graça, 2019 


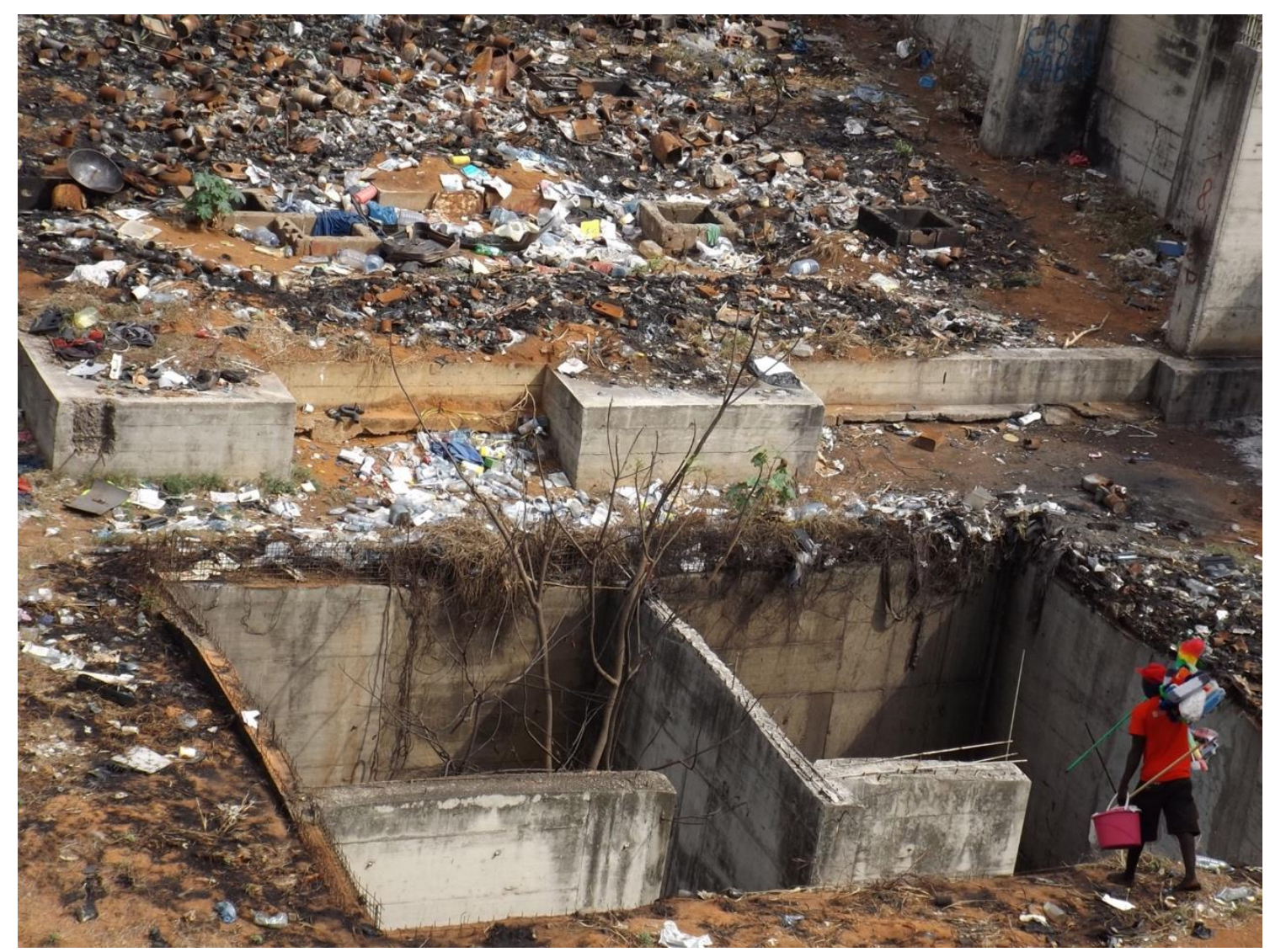

Falta de material, Sara Machado da Graça, 2019 


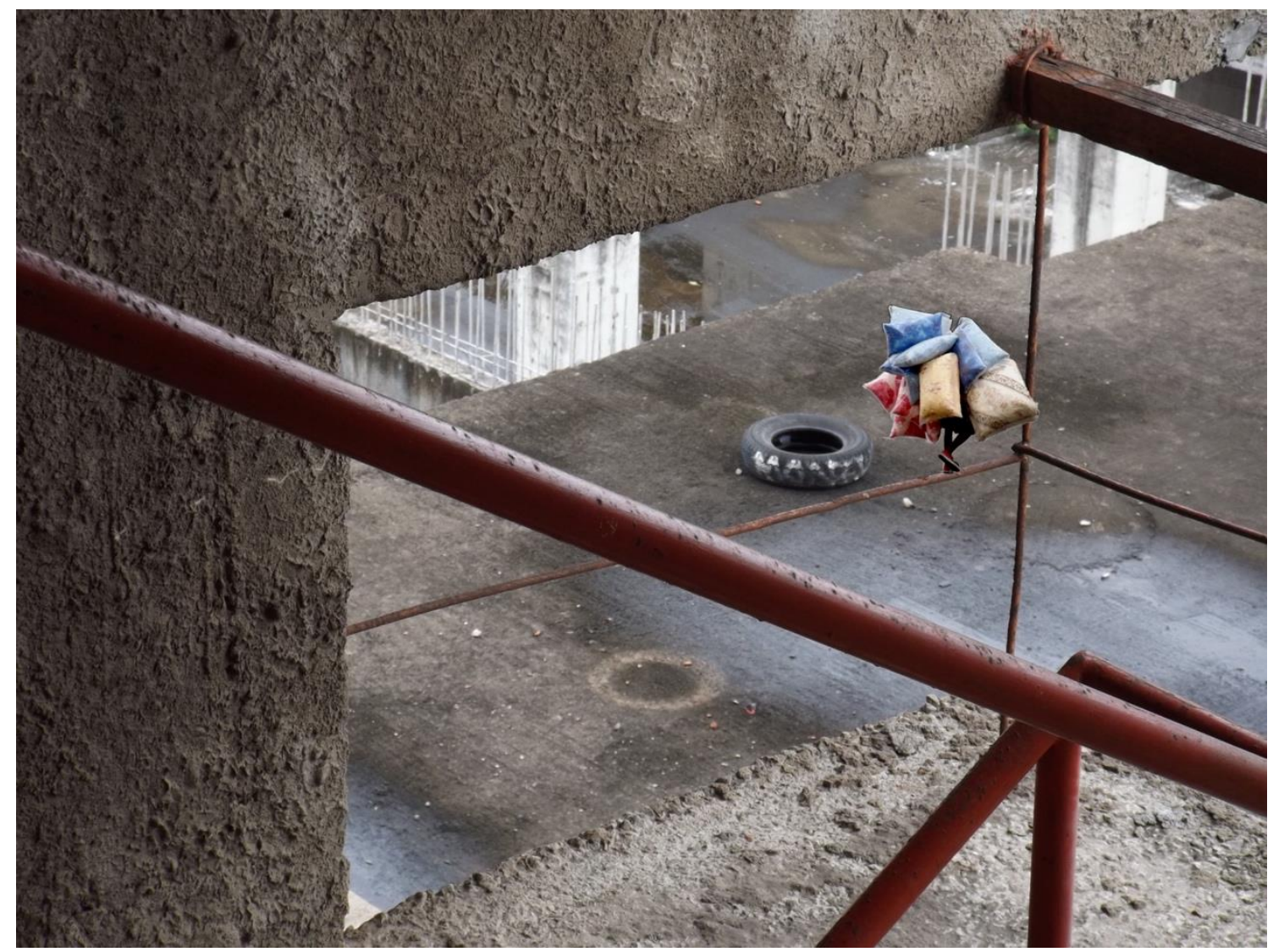

Funâmbulo com balão de almofadas, Sara Machado da Graça, 2019

\section{Referência bibliográfica}

Augé, Marc. (1994). Não-lugares, para uma introdução da antropologia da sobremodernidade. Papirus, Campinas.

Sara Machado da Graça reside atualmente em Maputo, Moçambique, onde leciona as disciplinas de Cenografia e Figurinos no Curso de Teatro da Escola de Comunicação e Artes da Universidade Eduardo Mondlane, trabalha também como programadora artística da Galeria/Associação Kulungwana. Continua a fazer trabalhos como cenógrafa e figurinista para teatro, cinema, dança e ópera, assim como curadoria para exposições.

$\bowtie$ sagadexam@gmail.com 